\title{
Nosocomial and community-acquired Legionella pneumonia: clinical comparative analysis
}

\author{
M.L. Pedro-Botet*, M. Sabria-Leal*, M. Haro**, C. Rubio*, \\ G. Gimenez*, N. Sopena*, J. Tor
}

Nosocomial and community-acquired Legionella pneumonia: clinical comparative analysis. M.L. Pedro-Botet, M. Sabria-Leal, M. Haro, C. Rubio, G. Gimenez, N. Sopena, J. Tor. CERS Journals Ltd 1995.

ABSTRACT: Previous reports have suggested that nosocomial and community Legionella pneumonia cases are similar. However, community and hospital characteristics, such as aquatic environment, antibiotic pressure (usage) and populations, are quite different, leading to the suspicion that Legionella infection may differ in the two settings.

Univariate and multivariate analyses were performed to compare demographic data, risk factors, clinical, radiological and outcome data between 125 nosocomial and 33 community-acquired cases of Legionella pneumophila infection.

Patients in the nosocomially acquired Legionella pneumonia (NALP) group were older than those in the community-acquired Legionella pneumonia (CALP) group. Univariate analysis showed that smoking habit, cough, thoracic pain, and extrapulmonary manifestations were more prevalent in the CALP group, whilst chronic lung disease and cancer were more prevalent in the NALP group. Moreover, patients in the NALP group were more likely to have received oxygen and corticosteroid therapy and also to have altered creatinine values than patients in the CALP group, whilst more patients in the latter group had altered alanine aminotransferase values. However, multivariate analysis failed to confirm most of these differences. Smoking habit and blood creatinine levels were the only variables remaining significant.

In conclusion, demographic, clinical, laboratory, radiological and outcome data in nosocomial and community-acquired Legionella pneumonia are quite similar. Eur Respir J., 1995, 8, 1929-1933.

Legionella pneumophila has been recognized as an important cause of community and nosocomial pneumonia. Experience accumulated since its first description in 1976 [1] has led to a good understanding of this infection both in the hospital and community environment. Despite the large number of reports of Legionella pneumonia infection [2-9], information concerning differences in clinical, radiological, and outcome aspects between nosocomial and community-acquired cases are very scarce. Previous reports have suggested that clinical aspects of nosocomial and community cases are similar [10]. The community and hospital characteristics, such as aquatic environment, antibiotic pressure (usage) and populations, are quite different and Legionella infection might differ in the two settings. The aquatic environment and antibiotic pressure may contribute to the selection of more virulent strains of L. pneumophila within the hospital.

The purpose of the present study was to compare by univariate and multivariate analysis the demographic data, risk factors, clinical and radiological data, and outcome of 125 nosocomial and 33 community-acquired cases of Legionella pneumophila pneumonia.
*Unitat de Malalties Infeccioses and **Servei de Pneumologia, Hospital Universitario Germans Trias i Pujol, Badalona, Universitat Autonoma de Barcelona, Spain.

Correspondence: M. Sabria-Leal

Can Domenech 10-12

08193-Bellaterra

Barcelona

Spain

Keywords: Community pneumonia

Legionella

Legionella pneumonia

nosocomial infection

nosocomial pneumonia

Received: February 281995

Accepted after revision August 171995

This research was made possible in part by FISS grant 90/0060.

\section{Setting}

The Hospital Universitario Germans Trias i Pujol is a 600 bed teaching institution, that operates as the reference hospital for a population of 700,000 inhabitants. It has an active Medicine and Surgery Department, Obstetric and Paediatric Services, Dialysis and Kidney Transplant Unit, and Intensive Care Unit. Legionella infection was detected as early as 1983 in the hospital. Despite the measures adopted, legionellosis has persisted as an endemic situation (5-15 cases.year ${ }^{-1}$ ), with two epidemic outbreaks during the summer of 1988 and 1989 (26 and 18 cases, respectively).

\section{Patient selection and study design}

One hundred and thirty six patients with nosocomiallyacquired Legionella pneumonia (NALP), and 34 patients 
with community-acquired Legionella pneumonia (CALP) were included in the study. We applied the Centers for Disease Control (CDC) [11] and World Health Organization (WHO) [12] criteria for diagnosis both of nosocomial infection and Legionella pneumonia One hundred and twenty two patients were diagnosed exclusively by a fourfold or greater rise in titre of indirect fluorescent antibody (IFA) (Legionella pneumophila serogroups 1-6; Labsystems 6109401) and 38 patients by direct fluorescent antibody (DFA) (Legionella pneumophila serogroups 1-10; Genetic Systems 0149-04) in respiratory specimens.

Legionella pneumophila serogroup 1 was isolated in 28 cases. Whilst nosocomial isolates showed a single chromosomal pattern, those for community isolates were quite different [13].

A retrospective review of all medical records from patients diagnosed as NALP and CALP was made from 1983 to 1985 (18 patients). From January 1985 to December 1992, the study was conducted prospectively (140 patients). Complete records were available in 125 nosocomial cases and in 33 community cases.

The cards of selected patients included demographic information, extrinsic and intrinsic risk factors, clinical and radiological manifestations, and evolution. We also registered analytical determinations corresponding to the first week after diagnosis was made. The clinical course was assessed for the development of respiratory or renal failure and shock. Case-fatality rates were determined for death directly attributable to Legionella pneumonia infection.

\section{Statistical analysis}

Data were analyzed by means of a statistical program for personal computer. Discrete variables were analysed by univariate analysis using Chi-squared. Comparison of groups with continuous variable distribution was performed by means of the Student's t-test. Multivariate analysis was performed by logistic regression. In all analyses, the level of significance was set at a p-value equal to 0.05 .

\section{Results}

\section{Demographic data}

Univariate analysis showed that patients in the NALP group were older than those in the CALP group (NALP group mean age $64 \pm 13 \mathrm{yrs}$ ), and CALP group mean age $48 \pm 15 \mathrm{yrs} ; \mathrm{p}>0,001)$. The male:female ratio was $2: 1$ in the NALP group, and 4:1 in the CALP group, but the difference was not statistically significant, either in the univariate or in the multivariate analysis (table 1).
Table 1. - Univariate and multivariate analysis of demographic data and risk factors for Legionella infection

\begin{tabular}{|c|c|c|c|c|}
\hline Demographic data & $\begin{array}{c}\text { NALP } \\
(\mathrm{n}=125)\end{array}$ & $\begin{array}{l}\text { CALP } \\
(\mathrm{n}=33)\end{array}$ & p-value ${ }^{+}$ & p-value ${ }^{++}$ \\
\hline Age yrs $($ Mean \pm SD $)$ & $64 \pm 13$ & $48 \pm 15$ & $0.001 *$ & 0.09 \\
\hline $\operatorname{Sex} \quad M / F$ & $84 / 41$ & $26 / 7$ & 0.19 & - \\
\hline \multicolumn{5}{|l|}{ Risk factors $\#$} \\
\hline Smoking habit & $66 / 121$ & $25 / 33$ & $0.02 *$ & $0.01 *$ \\
\hline Chronic lung disease & $67 / 122$ & $11 / 32$ & $0.03 *$ & 0.31 \\
\hline Cardiopathies & $20 / 122$ & $2 / 33$ & 0.21 & - \\
\hline Chronic renal failure & $19 / 122$ & $2 / 33$ & 0.25 & - \\
\hline Diabetes mellitus & $24 / 123$ & $5 / 33$ & 0.56 & - \\
\hline Cancer & $22 / 123$ & $0 / 33$ & $0.01 *$ & 0.87 \\
\hline Alcoholism & $40 / 120$ & $16 / 33$ & 0.10 & - \\
\hline Hepatic cirrhosis & $6 / 122$ & $0 / 32$ & 0.44 & - \\
\hline Intravenous drug abuser & r $\quad 2 / 122$ & $0 / 33$ & 1.00 & - \\
\hline AIDS & $2 / 122$ & $0 / 33$ & 1.00 & - \\
\hline Oxygen therapy & $59 / 123$ & $5 / 33$ & $0.001 *$ & 0.6 \\
\hline Corticosteroid therapy & $38 / 123$ & $0 / 33$ & $0.0002 *$ & 0.8 \\
\hline
\end{tabular}

\#: positive data/data available; +: univariate analysis; ${ }^{++}$: multivariate analysis; *: statistically significant. NALP nosocomiallyacquired Legionella pneumonia; CALP: community-acquired Legionella pneumonia; AIDS: acquired immune deficiency syndrome; M: male; F: female.

\section{Risk factors}

Among the intrinsic risk factors, smoking habit was more prevalent in the CALP group than in NALP group (76 versus $53 \% ; \mathrm{p}=0.02$ ), whilst chronic lung disease and cancer were more common in the NALP group than in the CALP group (54 and 18\% versus 3 and $0 \% ; \mathrm{p}=0.03$ and $\mathrm{p}=0.01$, respectively). NALP patients were also more likely to have received oxygen and corticosteroid therapy than CALP patients (47 and 30\% versus 15 and $0 \% ; \mathrm{p}=0.001$ and $\mathrm{p}=0.0002$, respectively). The difference for other risk factors, such as cardiopathies, chronic renal failure, diabetes, alcoholism, hepatic cirrhosis, acquired immune deficiency syndrome (AIDS) or intravenous drug abuse (IDA) was not statistically significant. Nevertheless, the logistic regression analysis indicated smoking as the only significant independent variable $(\mathrm{p}=0.01)$ (table 1$)$.

\section{Clinical and radiological manifestations}

Common clinical manifestations are shown in table 2 . Univariate analysis showed that cough $(\mathrm{p}=0.001)$, thoracic pain $(\mathrm{p}=0.04)$ and neurological $(\mathrm{p}=0.0002)$ and gastrointestinal $(\mathrm{p}=0.03)$ manifestations were more common in the CALP group than in NALP group. However, the logistic regression analysis failed to demonstrate a significant independent association for any variable (table 2).

The radiological features at presentation and during the evolution were similar in both groups (table $3)$. 
Table 2. - Univariate and multivariate analysis of clinical data of 125 NALP and 33 CALP patients

\begin{tabular}{|c|c|c|c|c|}
\hline & $\begin{array}{l}\text { NALP\# } \\
(\mathrm{n}=125)\end{array}$ & $\begin{array}{l}\text { CALP\# } \\
(\mathrm{n}=33)\end{array}$ & p-value ${ }^{+}$ & p-value ${ }^{++}$ \\
\hline Fever & $122 / 123$ & $33 / 33$ & 1.00 & - \\
\hline Cough & $65 / 123$ & $27 / 32$ & $0.001 *$ & 0.45 \\
\hline Expectoration & $44 / 123$ & $15 / 33$ & 0.30 & - \\
\hline Chest pain & $30 / 123$ & $14 / 33$ & $0.04 *$ & 0.12 \\
\hline $\begin{array}{l}\text { Initial absence of } \\
\text { respiratory symptoms }\end{array}$ & s $70 / 123$ & $15 / 33$ & 0.24 & - \\
\hline $\begin{array}{l}\text { Neurological } \\
\text { symptomatology }\end{array}$ & $23 / 123$ & $15 / 33$ & $0.0002 *$ & 0.08 \\
\hline Headache & 10 & 12 & & \\
\hline Confusion & 13 & 3 & & \\
\hline $\begin{array}{l}\text { Gastrointestinal } \\
\text { symptomatology }\end{array}$ & $19 / 123$ & $8 / 33$ & $0.03 *$ & 0.06 \\
\hline Abdominal pain & 9 & 0 & & \\
\hline Vomiting & 3 & 3 & & \\
\hline Diarrhoea & 7 & 5 & & \\
\hline
\end{tabular}

\#: positive data/data available; *: statistically significant; ${ }^{+}$: univariate analysis; ${ }^{++}$: multivariate analysis. For abbreviations see legend to table 1 .

Table 3. - Univariate and multivariate analysis of radiological manifestation of 125 NALP and 33 CALP patients

\begin{tabular}{lcccc}
\hline & $\begin{array}{r}\text { NALP\# } \\
(\mathrm{n}=125)\end{array}$ & $\begin{array}{c}\mathrm{CALP}^{\#} \\
(\mathrm{n}=33)\end{array}$ & $\mathrm{p}^{\text {-value }}{ }^{+}$ & p-value \\
& $88 / 121$ & $22 / 33$ & 0.65 & - \\
\hline $\begin{array}{l}\text { Unilateral infiltrates } \\
\text { Unilobar infiltrates }\end{array}$ & $96 / 121$ & $24 / 33$ & 0.58 & - \\
$\begin{array}{l}\text { Pleural effusion } \\
\begin{array}{l}\text { Development of } \\
\text { empyema }\end{array}\end{array}$ & $23 / 121$ & $9 / 31$ & 0.22 & - \\
$\begin{array}{l}\text { Development of } \\
\text { lung abscess }\end{array}$ & $2 / 122$ & $3 / 32$ & 0.10 & - \\
\hline
\end{tabular}

\#:positive data/data available; ${ }^{+}$: univariate analysis; ${ }^{++}$: multivariate analysis. For abbreviations see legend to table 1 .

\section{Laboratory findings}

Common laboratory findings are shown in table 4 . Neither peripheral white blood cell count, natraemia, aspartate aminotransferase (AST), alkaline phosphatase, gammaglutamyl transpeptidase (GGT), bilirubin, or arterial oxygen tension $\left(\mathrm{Pa}_{\mathrm{a}} \mathrm{O}_{2}\right)$, discriminated between the NALP and CALP groups. Univariate analysis showed that creatinine and alanine aminotransferase (ALT) were more commonly altered in the NALP group that in CALP group ( $\mathrm{p}=0.001$ and $\mathrm{p}=0.02$, respectively). However, only creatinine persisted as a significant independent variable in the multivariate analysis.

\section{Clinical course and outcome}

The clinical course and outcome of the 125 NALP and 33 CALP patients are shown in table 5. Respiratory failure was the most common complication in both groups (58\% in the NALP group versus $73 \%$ in the CALP group), followed by renal failure (15\% in the NALP group versus $9 \%$ in the CALP group) and shock (11\% in the NALP group versus $6 \%$ in the CALP group). No neurological sequelae were observed.
Table 4. - Univariate and multivariate analysis of laboratory findings of 125 NALP and 33 CALP patients

\begin{tabular}{|c|c|c|c|c|}
\hline & $\begin{array}{l}\text { NALP\# } \\
(\mathrm{n}=125)\end{array}$ & $\begin{array}{l}\text { CALP\# } \\
(\mathrm{n}=33)\end{array}$ & p-value ${ }^{+}$ & p-value ++ \\
\hline $\begin{array}{l}\text { Leucocyte count } \\
\qquad 10 \times 10^{9} \text { cells } \cdot \mathrm{L}^{-1}\end{array}$ & $84 / 21$ & $24 / 33$ & 0.71 & - \\
\hline $\begin{array}{l}\text { Blood urea nitrogen } \\
\quad\left(>8.6 \mathrm{mmol} \cdot \mathrm{L}^{-1}\right)\end{array}$ & $44 / 112$ & $7 / 32$ & 0.07 & - \\
\hline $\begin{array}{l}\text { Blood creatinine } \\
\qquad\left(>106 \text { umol } \cdot \mathrm{L}^{-1}\right)\end{array}$ & $51 / 107$ & $5 / 31$ & $0.001 *$ & $0.002^{*}$ \\
\hline Sodium $\left(<135 \mathrm{mEq} \cdot \mathrm{L}^{-1}\right)$ & $62 / 111$ & $16 / 31$ & 0.67 & - \\
\hline Chloride $\left(>100 \mathrm{mEq} \cdot \mathrm{L}^{-1}\right)$ & $68 / 98$ & $18 / 27$ & 0.78 & - \\
\hline AST $\left(>43 \mathrm{U} \cdot \mathrm{L}^{-1}\right)$ & $39 / 106$ & $17 / 30$ & 0.051 & - \\
\hline $\operatorname{ALT}\left(>53 \mathrm{U} \cdot \mathrm{L}^{-1}\right)$ & $35 / 105$ & $17 / 30$ & $0.021^{*}$ & 0.52 \\
\hline $\begin{array}{l}\text { Alkaline phosphatase } \\
\qquad\left(>121 \mathrm{U} \cdot \mathrm{L}^{-1}\right)\end{array}$ & $30 / 104$ & $9 / 30$ & 0.90 & - \\
\hline GGT $\left(>66 \mathrm{U} \cdot \mathrm{L}^{-1}\right)$ & $13 / 93$ & $13 / 28$ & 0.29 & - \\
\hline Bilirubin $\left(>20 \mathrm{mmol} \cdot \mathrm{L}^{-1}\right)$ & $13 / 95$ & $3 / 28$ & 0.90 & - \\
\hline$P \mathrm{a}, \mathrm{O}_{2}(<8.0 \mathrm{kPa})$ & $57 / 90$ & $21 / 27$ & 0.16 & - \\
\hline
\end{tabular}

\#: positive data/data available; +: univariate analysis; ${ }^{++}$: multivariate analysis; *: significant. AST: aspartate aminotransferase; ALT: alanine aminotransferase; GGT: gammaglutamyl transpeptidase; $\mathrm{Pa}_{\mathrm{a}} \mathrm{O}_{2}$ : arterial oxygen tension. For further abbreviations see legend to table 1 .

Table 5. - Univariate and multivariate analysis of clinical outcome of 125 NALP and 33 CALP patients

NALP $^{\#}$ CALP\# $^{\#}$-value ${ }^{+}$p-value ${ }^{++}$ $(\mathrm{n}=125) \quad(\mathrm{n}=33)$

Development of respiratory

\begin{tabular}{|c|c|c|c|}
\hline failure & $71 / 122$ & $24 / 33$ & 0.12 \\
\hline $\begin{array}{l}\text { Development of renal } \\
\text { failure }\end{array}$ & $18 / 121$ & $3 / 32$ & 0.6 \\
\hline Development of shock & $13 / 122$ & $2 / 32$ & 0.67 \\
\hline $\begin{array}{l}\text { Death directly attributable } \\
\text { to Legionella infection }\end{array}$ & $22 / 123$ & $2 / 33$ & 000 \\
\hline Death not attributable & & $1 / 32$ & 100 \\
\hline Case-fatality rate \% & 18 & 6 & \\
\hline
\end{tabular}

\#: positive data/data available; +: univariate analysis; ++: multivariate analysis. For abbreviations see legend to table 1 .

Twenty eight patients (22\%) died in the NALP group versus three patients (9\%) in the CALP group. However, considering deaths directly attributable to Legionella infection, the case-fatality rate was $18 \%$ in the NALP group and $6 \%$ in the CALP group.

No difference concerning course and outcome between the groups was significant, either using univariate or multivariate analysis.

\section{Discussion}

The demographic characteristics of our patients are similar to those reported previously $[6,8,10,14]$. Both in NALP and CALP groups, the risk of acquiring legionellosis was increased in males. Whilst in the NALP group, old age and intrinsic and extrinsic risk factors were common in many patients, reflecting the hospital population 
characteristics, the typical patient in the CALP group was a smoking and drinking middle-aged man, with a low frequency of pre-existing chronic diseases, except for chronic lung disease. These observations are similar to those of WoOdHEAD and Macfarlane [9], suggesting that pre-existing chronic diseases in CALP are not an essential condition to acquire Legionella pneumonia. Our study suggests that the clinical findings of nosocomial and community-acquired Legionella pneumophila pneumonias are quite similar. Fever was the most common finding. The absence of respiratory symptomatology during the first $24 \mathrm{~h}$ of illness was common in both groups, thus making the early diagnosis of pneumonia difficult, especially in the NALP group and when extrapulmonary symptoms were present. However, either cough, chest pain, dyspnoea or respiratory insufficiency generally develops in most patients after the first $72 \mathrm{~h}$ of illness.

The extrapulmonary findings in Legionella pneumonia are common $[6,9,15-20]$, the pathogenesis of which may be diverse $[15,16,21,22]$. The incidence of neurological and gastrointestinal manifestations was lower in our series than in other published studies $[6,9,10,20$, 23]. However, vomiting and diarrhoea were more common in the CALP (9 and 15\%, respectively) than in NALP group (2 and 6\%, respectively). Furthermore, headache was more frequent in the CALP $(36 \%)$ than in NALP group $(8 \%)$. When considered globally, the differences observed in the neurological and gastrointestinal manifestations were significant in the univariate analysis. Two reasons account for these differences in our series. The CALP patients enter the hospital late because of the lack of specifity in initial symptomatology, allowing the extrapulmonary symptomatology to develop. In our hospital and in hospitals with endemic legionellosis, the diagnosis and the onset of treatment for nosocomial Legionella pneumonia is immediate because of the high level of suspicion. This makes the extrapulmonary manifestations of Legionella infection less likely to be observed in this context.

The frequency of laboratory abnormalities in our patients was similar to that noted in other published studies $[6,9]$. Abnormal liver function was observed in 1 out of 3 of the patients in both groups. Interestingly, the patients in the CALP group presented higher levels of ALT than the patients in the NALP group, a difference that was statistically significant in the univariate analysis. Furthermore, the NALP patients more frequently presented altered renal parameters than the CALP patients. The fact that many patients in the NALP group had previous nephropathies and the older age in this group accounted for these differences.

Unilobar infiltrate was the usual finding on admission chest radiographs in both groups, as noted in other published studies [10, 24-26]. Development of empyema or pulmonary abscess were uncommon accounting for $5 \%$ of the whole series. No significant difference was observed in any radiological variable between the patients groups.

As in other series, the most common complication was respiratory failure [9]. The fact that $51 \%$ of our patients had chronic lung disease and 59\% were heavy smokers partially explains this finding.

The case fatality rate was 18 and $6 \%$ for the NALP and CALP groups, respectively. Despite the lower percentage of patients who died in the CALP group this difference was not statistically significant in either the univariate analysis or multivariate analysis, probably due to the few cases included in the CALP group. The CALP group has been observed in many series as having a lower mortality rate than NALP $[9,10]$. Our case fatality rate in both groups was lower than the reported mortality for nosocomial and community-acquired cases in other series $[6,10,27]$. The inclusion of erythromycin in the initial combined therapy for all nosocomial pneumonia in our hospital, and the routine use of this antibiotic for the community pneumonias in our country accounted for this low rate.

We emphasize that $70 \%$ of the patients in the NALP group who died were under corticosteroid therapy. In our NALP group, corticosteroid therapy and shock were associated with a higher mortality rate in one logistic regression analysis model [23].

In conclusion, demographic, clinical, laboratory and radiological data of Legionella pneumonia in our hospitalized and community patients were quite similar and it did not justify separation of these entities. Many of the distinctions between the groups observed in the univariate analysis probably reflect differences in the hospital and community population characteristics rather than in virulence of the Legionella infection. Moreover, multivariate analysis failed to confirm almost all of them.

\section{References}

1. Fraser DW, Tsai T, Orenstein W, et al. Legionnaires' disease: description of an epidemic of pneumonia. $N$ Engl J Med 1977; 297: 1189-1197.

2. Storch G, Baine WB, Fraser DW, et al. Sporadic community-acquired Legionnaire's disease in the United States. Ann Intern Med 1979; 90: 529-532.

3. Bouza E, Rodriguez-Creixems M. Legionnaires' disease in Spain. In: Thornsberry C, Ballows A, Feeley JC, Jakubowsky W, eds. Legionella. Proceedings of the 2nd International Symposium, Washington DC, American Society for Microbiology 1984; pp. 15-17.

4. Meenhorst PL, van der Meer JWM, Borst J. Sporadic cases of Legionnaires' disease in the Netherlands. Ann Intern Med 1979; 90: 529-532.

5. Broome CV, Fraser DW. Epidemiologic aspects of legionellosis. Epidemiol Rev 1979; 1: 1-16.

6. Kirby BD, Snyder KM, Meyer RD, Finegold SM. Legionnaires' disease: report of 65 nosocomially-acquired cases and review of the literature. Medicine (Balt) 1980; 59: 188-205.

7. Woodhead MA, Macfarlane JT. The protean manifestations of Legionnaires' disease. J R Coll Phys (Lond) 1985; 19: 224-230.

8. Bartlett CLR. Sporadic cases of Legionnaires' disease in Great Britain. Ann Intern Med 1979; 90: 592-595.

9. Woodhead MA, Macfarlane JT. Legionnaires' disease: a review of 79 community-acquired cases in Nottingham. Thorax 1986; 41: 635-640.

10. Helms CM Viner JP, Weisenburger DD, Chiu LC, 
Renner ED, Johnson W. Sporadic Legionnaires' disease: clinical observations on 87 nosocomial and community-acquired cases. Am Med J Science 1984; 288: $2-12$.

11. Pedro-Botet ML, Sabria-Leal M, Espinosa Ll, et al. Marcadores moleculares de la legionellosis nosocomial en el hospital Germans Trias i Pujol de Badalona. Medi Clin (Barc) 1992; 99: 761-765.

12. Garner JS, Jarvis WR, Emori TG, Horan TC, Hughes JM. CDC definitions for nosocomial infections 1988. Am J Infect Control 1988; 16: 128-140.

13. Report. Epidemiology, prevention and control of legionellosis. Memorandum from a WHO meeting. Bull WHO 1990; 68(2): 155-164.

14. Beaty HN. Clinical features of legionellosis. In: Thornsberry C, Balows A, Feeley JC, Jakubowsky W, eds. Legionella. Proceedings of the 2nd International Symposium. Washington DC, American Society for Microbiology, 1984; pp. 6-10.

15. Humayun HM, Bird TJ, Daugirdas JT, Fruin RC, Shawky MM. Legionnaires' disease bacillus in bone marrow. Can Med Assoc J 1981; 125: 1084-1085.

16. Wats JC, Hicklin MD, Thomason BM, Callaway CS, Levine AJ. Fatal pneumonia caused by Legionella pneumophila serogroup 3: demonstration of the bacilli in extrathoracic organs. Ann Intern Med 1980; 92: 186-188.

17. Holt P. Legionnaires' disease and abscess of appendix. Br Med J 1981; 282: 1035-1036.

18. Dorman Sa, Hardin NJ, Winn WC Jr. Pyelonephritis associated with Legionella pneumophila serogroup 4. Ann Intern Med 1980; 93: 835-837.
19. White HJ, Felton WW, Sun CN. Extrapulmonary histopathologic manifestations of legionnaires' disease. Arch Pathol Lab Med 1980; 104: 287-289.

20. Nordstrom K, Kallings I, Dahnsjo H, Clemens F. An outbreak of legionnaires' disease in Sweden: report of sixty eight cases. Scand J Infect Dis 1983; 15: 43-55.

21. Baine WB, Rasheed JK, Mackel DC, Bopp CA, Wells JG, Kaufmann AF. Exotoxin activity associated with the legionnaires' disease bacterium. J Clin Microbiol 1979; 9: 453-456.

22. Edelstein PH, Meyer RD, Finegold SM. Isolation of Legionella pneumophila from blood. Lancet 1979; 1: 750-751.

23. Sabria-Leal M, Pedro-Botet ML, Condom Mundo MJ, et al. Analisis clinico descriptivo de 119 casos de neumonia nosocomial por Legionella pneumophila. IV Reunion Sociedad Enfermedades Infecciosas y Microbiologia Clinica. Santiago de Compostela, 1991.

24. Kirby BD, Peck H, Meyer RD. Radiographic features of legionnaires' disease. Chest 1979; 76: 562-565.

25. Storch GA, Sagel SS, Baine WB. The chest roentgenogram in sporadic cases of legionnaires' disease. $J$ Am Med Assoc 1981; 242: 587-590.

26. Domingo Ch, Roig J, Planas F, Bechini J, Teresa M, Morera J. Radiographic appearance of nosocomial legionnaires' disease after erythromycin treatment. Thorax 1991; 46: 663-666.

27. England AC III, Fraser DW. Plikaytis BD, Tsai TF, Storch G, Broome CV. Sporadic legionellosis in the United States: the first thousand cases. Ann Intern Med 1981; 94: 164-170. 